\title{
Effects of intrastriatal blockade of glutamatergic transmission on the acquisition of T-maze and radial maze tasks
}

\author{
W. Hauber and W. J. Schmidt \\ Biologisches Institut, Universität Stuttgart, Stuttgart, Federal Republic of Germany
}

Accepted December 21, 1988

\begin{abstract}
Summary. Prefrontal cortex and neostriatum constituting the prefrontal system are connected by glutamatergic neurones. The involvement of this corticostriatal projection in control of maze performance of rats was investigated. Glutamatergic transmission mediated by N-methyl-D-aspartate (NMDA) receptors was blocked by intrastriatal injections of dl-2-amino-5-phosphonovaleric acid (AP-5) $(50$ nmole in $0.5 \mu \mathrm{l})$. In experiment 1 , intrastriatal AP-5 was found to increase the number of errors during acquisition of a delayed alternation task in a T-maze. In experiment 2, the effect of intrastriatal AP-5 on acquisition of different 8 arm maze tasks was investigated. AP- 5 did not affect the number of reentries on spontaneous and reinforced alternation; pre- and postdelay errors on delayed alternation were not altered. Therefore, intrastriatal NMDA receptor blockade impairs acquisition of a delayed alternation in a Tmaze, while intrastriatal blockade of NMDA receptors does not affect acquisition of different 8 arm maze tasks. The impairment in the T-maze task appears not to be due to deficient acquisition of spatial information per se, since 8 arm maze performance is intact. Instead, repeated delays in the T-maze task seem to be the critical component that gives difficulties in acquisition. These difficulties in bridging successive temporal discontiguities were attributed to an increased susceptibility to external and internal interfering stimuli during delays. Thus, striatal NMDA receptors within the prefrontal system may be involved in correct response retention over the duration of delays.
\end{abstract}

Keywords: Learning and memory, interference, striatum, glutamate, NMDA receptor, AP-5, rat.

\section{Introduction}

The mammalian neostriatum is involved in planning and control of motor behavior but may also subserve for some "cognitive" functions (Divac and Öberg, 1979). Especially tasks of delayed response type require intact striatal processing in primates (Divac and Öberg, 1979). The adequate and sensitive 
paradigm for rodents is a delayed alternation task in the T- or Y-maze. Mechanical or neurotoxic lesions in the antero-dorsal striatum of rats produce severe impairments in delayed alternation tasks and increase alternation to chance level (Pisa, 1983; Wikmark et al., 1973). In addition, amphetamine also induces a spatial alternation deficiency that is characterized by perseverative tendencies and alternation below chance level. This perturbation is primarily attributed to a stimulation of the nigro-striatal dopaminergic system (Katz and Schmaltz, 1981).

In the same task a similar impairment is observed following damage to the medial prefrontal cortex, the cortical area from which the cortico-striatal neurones originate (Dunnet and Iversen, 1981; Simon and Le Moal, 1984). These and other findings (Divac and Öberg, 1979) indicate a close functional relationship between these two structures, which have led to the "prefrontal systems"-hypothesis (Rosvold, 1968). According to this hypothesis related areas of both structures may be implicated in similar functions.

Prefrontal cortex and striatum are connected by neurones which are arranged in a highly topographic manner and utilize most probably glutamate, an excitatory amino acid, as its neurotransmitter (Fonnum, 1984; Nieuwenhuys, 1985; Sandberg et al., 1985). Glutamate is thought to act at least at three distinct receptor subtypes which are termed N-methyl-D-aspartate (NMDA), kainate and quisqualate receptor according to the preferred agonists. It is well established that the neostriatum is abundant with NMDA receptors (Monaghan and Cotman, 1985; Olvermann et al., 1984) and some behavioral functions of striatal glutamate mediated by NMDA receptors have been recently shown. Striatal NMDA receptor antagonism in rats enhanced sniffing (Schmidt, 1986), rearing, locomotion and increased switching from one behavioral activity to another (Schmidt and Bury, 1988).

Lesions of dopaminergic terminals within the medial prefrontal cortex, the origin structure of glutamatergic cortico-striatal neurones produce quite similar behavioral effects (Schmidt and Bubser, 1987). Thus, striatal NMDA receptor blockade and prefrontal dopamine deficiency act in the same direction. With regard to these behaviors it has been shown, that striatal NMDA antagonism produces changes in the same direction as striatal dopamine agonism and in turn, NMDA agonism and dopamine antagonism within the striatum act in the same direction. These findings led to the hypothesis that, in behavioral terms, dopamine and glutamate exert opposite actions within the neostriatum (Schmidt, 1986).

The first experiment of the present study addresses two questions:

(1) is the neurotransmitter glutamate critically involved in the control of delayed alternation,

(2) what are the behavioral consequences of blocked NMDA receptors in the striatum as compared to mechanical or 6-hydroxy-dopamine lesions in the prefrontal cortex?

We employed a delayed alternation task in a T-maze, which constitutes a 
particular sensitive test to damage of the frontal cortex (Fuster, 1981; Markowitsch and Pritzel, 1977), as well as integrity of antero-dorsal striatum (Wikmark et al., 1973). Since spatial alternation seems to be a congenital explorative pattern of rats, requirement of this task may be well adjusted to a shifting strategy of this species (Douglas and Isaacson, 1965; Montgomery, 1954). To detect possible glutamatergic involvement in the control of delayed alternation, NMDA receptors were blocked by intrastriatal injections of dl-2-amino-5-phosphonovaleric acid (AP-5). AP-5 is a potent, competitive NMDA receptor blocker, which crosses the blood brain barrier very inefficiently. Using AP-5 we examined in our first experiment effects of intrastriatal NMDA receptor blockade on acquisition of delayed alternation in a T-maze.

Results indicate that delayed alternation is impaired following intrastriatal injections of AP-5. As this resulting deficit may be due to an impaired spatial memory, we studied in a further experiment different alternation behaviors (spontaneous, reinforced, delayed alternation) in an 8 arm radial maze following intrastriatal injections of AP-5. The results show that 8 arm maze alternation is not affected by intrastriatal NMDA receptor blockade.

\section{Materials and methods}

\section{Subjects}

Male Sprague-Dawley rats weighing 270-310g (Interfauna, Tuttlingen, FRG) were used for both experiments. They were housed -5 per cage - in a colony room at constant conditions (light from 6 a.m. -6 p.m., temperature $22 \pm 3^{\circ} \mathrm{C}$ ), had free access to water and received $15 \mathrm{~g}$ laboratory chow per animal each day.

\section{Surgery}

Stereotaxic surgery was done under ketamine $30 \mathrm{mg} / \mathrm{kg} / \mathrm{xylazine} 2 \mathrm{mg} / \mathrm{kg}$ anaesthesia using a Trent Wells instrument. Corresponding to the method described by Havemann et al. (1983), permanent guide cannulae $(0.8 \mathrm{~mm}$ in diameter, length $12 \mathrm{~mm})$ were bilaterally implanted and were aimed at the caudate putamen, but the tip of the cannulae went no further then to the surface of the brain. The guide cannulae were fixed to the skull using metal screws and dental acrylic cement. Beginning 2 days after surgery, bilateral intrastriatal injections were performed in the nonanesthetized rats with cannulae $(0.45 \mathrm{~mm}$ in diameter $)$ attached by silicone tubes to two $5 \mu 1$ Hamilton microliter syringes. The injection site was AP 2.0 (anterior to bregma), $\mathrm{L} \pm 2.0, \mathrm{~V} 5.0$ according to the atlas of Paxinos and Watson (1982) with the incisor bar $3.3 \mathrm{~mm}$ below the interaural plane. Volumes of $0.5 \mu 1$ were simultaneously injected (over $10 \mathrm{~s}$ ) and the cannulae were left in position for $30 \mathrm{~s}$ to allow diffusion.

\section{Intrastriatal injection}

dl-2-amino-5-phosphonovaleric acid (Sigma, Taufkirchen, FRG) was dissolved in a minimum quantity of $\mathrm{NaOH}$, diluted with destilled water and adjusted to $\mathrm{pH} 7.5$ using $\mathrm{HCl}$. Aliquots of $10 \mu \mathrm{g}$ in $0.5 \mu \mathrm{l}$ ( $50 \mathrm{nmole})$ were simultaneously injected to each striatum. Vehicle injections $(0.5 \mu \mathrm{l})$ served as controls.

In this study two paradigms were used. Experiment 1 was done in a T-maze, experiment 2 in 8 arm radial maze. 


\section{Experiment 1: effect of intrastriatal AP-5 on acquisition of delayed alternation in a T-maze}

Apparatus

The T-maze, similar to that described by Wikmark et al. (1973), was made of plastic coated wood with $35 \mathrm{~cm}$ high walls and $20 \mathrm{~cm}$ wide corridors. The stem was divided by an opaque and manually operated guillotine door into a start box, $30 \mathrm{~cm}$ and a runway, $60 \mathrm{~cm}$. At the distal end of both other arms $(70 \mathrm{~cm}$ long) a food cup was located.

\section{Procedures}

Adaption. The procedure was designed with reference to the description by Wikmark et al. (1973). Animals (N (cap.) $=10$ ) were adapted during 3 days, two 5 min sessions per animal were given daily. On day 1 of adaption, the guillotine door was removed, both arms were baited and each rat was left in the maze for $5 \mathrm{~min}$. On day 2 the door was introduced, the animal was repeatedly placed into the start box and immediately released. The rats were shaped to enter straightaway one of the arms shortly after their release. On day 3 rats were trained to respond promptly in 10 consecutive choices. Between the choices a rat remained into the start box.

Surgery. On day 4 stereotaxic surgery was done and after recovery the experiment was started on day 7.

Delayed alternation. The animals were randomly assigned in two groups receiving AP$5(\mathrm{~N}$ (cap.) $=5)$ or vehicle $(\mathrm{N}(\mathrm{cap})=5$.$) . After the injection procedure a rat was placed$ back in the home cage up to the onset of behavioral testing for 5 min. Each rat was given 11 choices a day for 9 consecutive days. On the initial choice (not scored) both arms were baited. On each of the following choices the animal was rewarded with a food pellet ( $45 \mathrm{mg}$, Noyes) for entering that arm which was not visited on the previous run, i.e. an arm was baited until the rat responded to it. Thus the animal was only rewarded when alternating. Errors, i.e. successive choices of the same arm were scored by video observation, an arm entry was defined as four paws inside an arm. Following each choice the rat was manually returned into the start box for a delay of $30 \mathrm{~s}$.

\section{Experiment 2: effect of intrastriatal AP-5 on spontaneous, reinforced and delayed alternation in a radial maze}

\section{Apparatus}

The employed 8 arm radial maze was similar in design to that of Olton and Samuelson (1976). It consisted of an octagonal central platform $(50 \mathrm{~cm}$ wide) surrounded by 8 equally spaced radial arms $(70 \mathrm{~cm}$ long $\times 17 \mathrm{~cm}$ wide $\times 35 \mathrm{~cm}$ high), made of plastic coated wood. Food cups were placed at the distal end of 7 arms. The remaining arm was the start arm, divided by an opaque and manually operated guillotine door into a start box, $30 \mathrm{~cm}$ and a runway, $40 \mathrm{~cm}$. The maze remained in a fixed position in the room, but the start arm was varied every day at random.

\section{Procedures}

In this paradigm, 3 tests were performed using the same rats $(\mathrm{N}(\mathrm{cap})=10$.$) in the following$ order:

Adaption. On day 1 animals were placed in the radial maze with their home cagemates and allowed to explore the maze for $15 \mathrm{~min}$. On day 2 and 3 each rat was placed in the maze individually for $5 \mathrm{~min}$. On day 4 stereotaxic surgery was done, and after recovery the experiment was started on day 7 . The animals were randomly assigned in two groups 


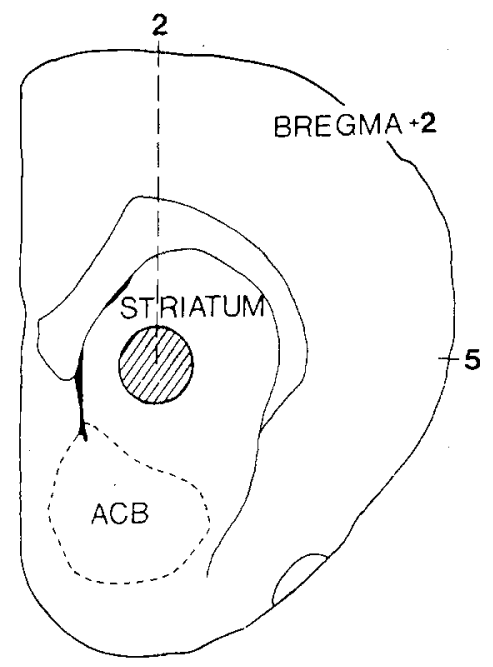

Fig. 1. Schematic drawing of the injection site in the antero-dorsal striatum of one hemisphere. The coordinates were AP 2.0 (anterior to bregma) $\mathrm{L} \pm 2.0, \mathrm{~V} 5.0$ according to the atlas of Paxinos and Watson (1982) with the incisor bar fixed $3.3 \mathrm{~mm}$ below the interaural plane

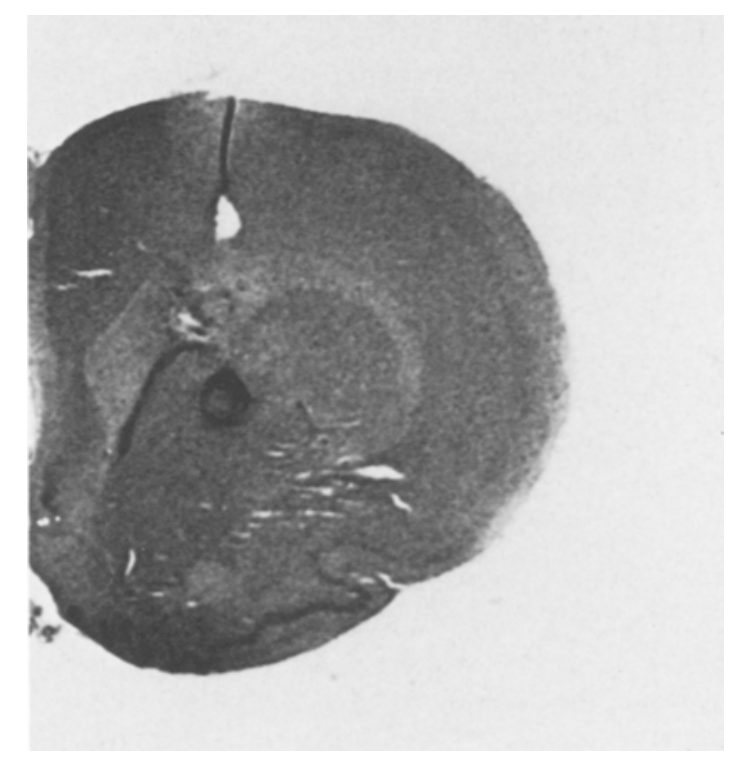

Fig. 2. Photograph of the injection site in the antero-dorsal striatum of one hemisphere (see also Fig. 1)

receiving AP-5 $(\mathrm{N}$ (cap.) $=5)$ or vehicle $(\mathrm{N}(\mathrm{cap})=5$.$) . After the injection procedure a rat$ was placed back in the home cage up to the onset of behavioral testing for $5 \mathrm{~min}$.

Spontaneous alternation. All food cups were removed from the maze. Each animal was placed in the box of the start arm and the guillotine door was opened immediately. A session lasted until all remaining 7 arms were entered or $10 \mathrm{~min}$ had elapsed. An arm entry 


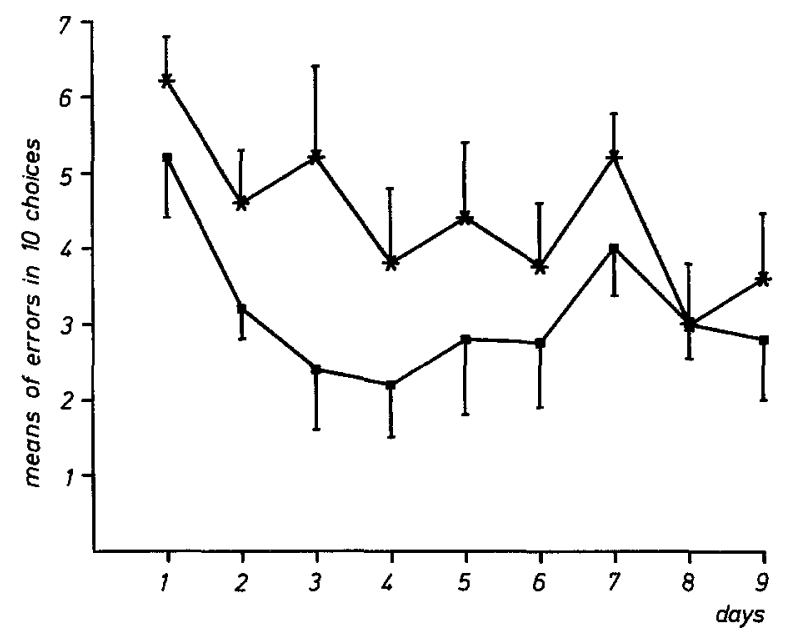

Fig. 3. Effect of intrastriatal injections of AP-5 on acquisition of delayed alternation in a T-maze (experiment 1). Means of errors of vehicle control $(\boldsymbol{\square}, \mathrm{N}$ (cap.) $=5,0.5 \mu \mathrm{l}$ vehicle) and AP- 5 treated rats $\left({ }^{*}, \mathrm{~N}\right.$ (cap.) $=5,50$ nmole in $0.5 \mu 1$ ) in 10 choices on 9 consecutive days. ANOVA revealed a significant difference of groups $(F(1,72)=9.06, p<0.005)$

was defined as four paws inside an arm and was scored by video observation. The number of reentries during the first seven choices and the number of reentries (including the start arm) until all arms were visited, were counted. Video recording also permitted an evaluation of the sequence of arm entries to observe possible exploration patterns in different tests. This test was performed on 3 consecutive days with one session daily for each animal.

Reinforced alternation. Following spontaneous alternation one session was interposed on day 10 to adapt undrugged animals to the baited maze. All arms except the start arm contained a baited food cup (pellet; $45 \mathrm{mg}$, Noyes). After adaption alternation reinforced by food was performed with the same procedure as described for spontaneous alternation.

Delayed alternation. Following reinforced alternation, this test was started on day 14 . The procedure was the same as described except that a delay of $30 \mathrm{~s}$ was interposed between the fifth and sixth choice. The rat was removed from the fifth choosen arm and placed into the start box for delay. The number of pre- and postdelay errors i.e. entries in previously visited arms were recorded.

\section{Histology}

Following the behavioral studies the brains were removed, fixed, sectioned and stained with cresyl violet to verify the injection sites. Only those rats in which the cannulae reached the coordinates $\pm 0.5 \mathrm{~mm}$ are considered (Figs. 1 and 2).

\section{Statistics}

The data of experiment 1 are presented as means of errors (false arm entries) ( \pm SEM) in 10 choices per day. These data were submitted to an analysis of variance (ANOVA) with groups and days as factors. The data of experiment 2 are presented as means of reentries (spontaneous, reinforced alternation) or errors (delayed alternation) ( $\pm \mathrm{SEM}$ ) of rats from both groups during 3 consecutive sessions ( 1 session a day). Statistical significance is calculated using Student's t-test (two-tailed). Differences were considered to be significant if the P-value is less then 0.05 . 

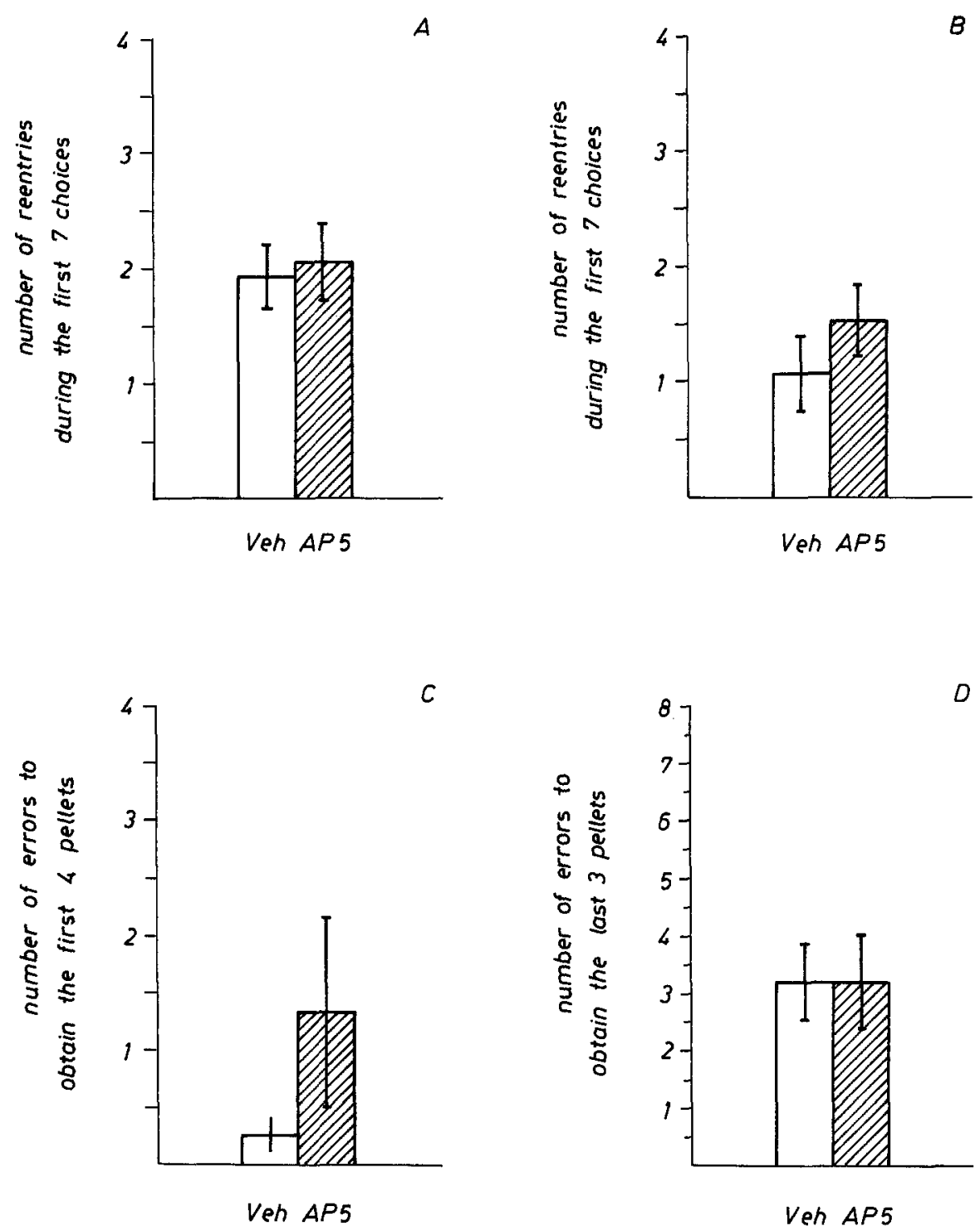

Fig. 4. Effect of intrastriatal injections of AP-5 (dotted columns, $N$ (cap.) $=5,50$ nmole in $0.5 \mu \mathrm{l}$ ) and vehicle (light columns, $\mathrm{N}$ (cap.) $=5,0.5 \mu \mathrm{l}$ vehicle) on different radial maze tasks (Statistical significance is calculated by Student's t-test, two-tailed). A Spontaneous alternation means of reentries during the first 7 choices. Comparison of errors of both groups from 3 consecutive sessions revealed no significant difference $(\mathrm{t}(28)=0.29, \mathrm{p}>0.05$ n.s.). B Reinforced alternation means of reentries during the first 7 choices. Comparison of reentries of both groups from 3 consecutive sessions revealed no significant difference $(\mathrm{t}(28)=1.36, \mathrm{p}>0.05$ n.s.). $\mathrm{C}$ Delayed alternation means of predelay errors. Comparison of reentries of both groups from 3 consecutive sessions revealed no significant difference $(t(28)=1.71, p>0.05$ n.s.). D Delayed alternation means of postdelay errors. Comparison of errors of both groups from 3 consecutive sessions revealed no significant difference $(\mathrm{t}(28)=0.12, \mathrm{p}>0.05 \mathrm{n} . \mathrm{s}$.) 


\section{Results}

\section{Experiment 1 (T-maze)}

Intrastriatal administration of AP-5 impaired delayed alternation as shown in Fig. 3. Analysis of variance (ANOVA) with days and groups as factors analysed revealed a significant effect of group $F(1,72)=9.06, p<0.005$, days $\mathrm{F}(8,72)=2.16$ and interaction $\mathrm{F}(8,72)=2.16, \mathrm{p}<0.05$ respectively. AP-5 treated animals made, except on day 8 , more errors than controls of the same day. Total means of all errors of all nine days also differed clearly (controls: 3.15, SEM \pm 0.33 , AP-5 treated: 4.4, SEM \pm 0.35 ). Both groups of this experiment also appeared to show a slight improvement [indicated by negative slopes of regression straight lines $\mathrm{m}(\mathrm{AP}-5)=-0.25 ; \mathrm{m}($ Vehicle $)=-0.11]$ accompagnied at least for the AP-5 treated group by a high variability in error rates on consecutive days.

\section{Experiment 2 (8 arm maze)}

Spontaneous alternation. Efficiency of spontaneous alternation, calculated by counting the number of reentires during the first 7 choices, appeared not to be affected following intrastriatal administration of AP-5. Data analysis showed no significant differences between the number of reentries of both groups, as indicated in Fig. $4 \mathrm{~A}(\mathrm{t}(28)=0.29, \mathrm{p}>0.05$ n.s.).

Reinforced alternation. Examination of reinforced alternation showed that animals which have received intrastriatal injections of A.P-5 performed as well as controls (Fig. $4 \mathrm{~B}$ ). Comparison of the number of reentries revealed that groups did not differ statistically significantly $(t(28)=1.36, p>0.05$ n.s.).

Delayed alternation. As depicted in Fig. $4 \mathrm{C}$ interposition of a delay (30 s) between choices 4 and 5 seemed to affect predelay performance of AP-5 treated animals, but no significant changes could be detected comparing the number of errors of both groups ( $\mathrm{t}(28)=1.71, \mathrm{p}>0.05$ n.s.). Postdelay performance of rats that have received intrastriatal AP-5 injections also exhibited no deterioration. The number of errors of both groups did not differ significantly $(\mathrm{t}(28)=0.12, \mathrm{p}>0.05$ n.s.) (Fig. 4D).

\section{Discussion}

We report here that intrastriatal NMDA receptor antagonism impairs acquisition of a delayed alternation task in a T-maze, while acquisition of different 8 arm maze tasks (spontaneous, reinforced, delayed alternation) is unaffected.

Intrastriatal NMDA receptor blockade following stereotaxic injection of AP-5 produces an impairment in acquisition of delayed alternation in the Tmaze. This impairment is characterized by a slight and inconstant improvement over time and mean performance below chance level. Therefore the conclusion may be justified that AP-5 does not completely disrupt but inhibit or retard learning of this task, which is of interest with regard to underlying mechanisms 
of this learning deficit (see below). This perturbation seems not to be due to a sensorimotor debility, since ataxic symptoms are not observed at the dose used here (50 nmole). Turski et al. (1988) observed an increase of muscle tone following intrastriatal injection of AP-7 (0.01-1 nmole), a more potent analogon of AP-5. These data are conflicted by studies reporting of muscle relaxant properties of AP-7 and other NMDA receptor antagonists in genetically spastic rats (Turski, 1988), increased locomotion and stereotyped sniffing following intrastriatal injection of AP-5 or AP-7 at the same dose used here (Schmidt, 1986; Scheel-Krüger and Vrijmoed-De Vries, 1986) or intraventricular injections of AP-5 (0.3 $\mu$ mole) (Koek et al., 1987). The observed differences may be partly explained by different injection sites within the neostriatum and it is possible that more ventral parts of the neostriatum participate in regulation of muscle tone in rats. Our present result indicates a specific involvement of striatal NMDA receptors in control of delayed alternation in the T-maze which has been termed as "cognitive" deficit by Divac and Öberg (1979).

There is further evidence that impaired acquisition of this task may depend on NMDA receptor blockade: ketamine, a dissociative anaesthetic like phencyclidine (PCP) known to antagonize noncompetitively the effect of NMDA sensitive glutamate receptors (Anis et al., 1983; Martin and Lodge, 1985) as well as MK-801, a novel and highly specific NMDA receptor antagonist produced a similar perturbation in the same task following systemic administration (Hauber, 1988; Bischoff et al., 1988; Alessandri et al., 1988). The present finding suggests a critical role of striatal NMDA receptors in control of delayed alternation and supports the "prefrontal systems"- hypothesis. Our result is corroborated by previous findings that mechanical or neurotoxic lesions in medial prefrontal cortex as well as the antero-dorsal striatum produce similar impairments (see Introduction) as seen here, but emphasizes intact glutamatergic cortico-striatal processing to acquire delayed alternation.

There is another aspect of this result with regard to a behavioral antagonism of dopamine and glutamate in the striatum (see Introduction): although using a somewhat different T-maze task, Katz and Schmaltz (1981) found preseverative tendencies in spatial alternation after amphetamine administration which were primarily attributed to a stimulation of the nigro-striatal dopamine system. Despite limitations in comparability for methodological reasons, a functional antagonism of glutamate and dopamine in alternation behavior in a T-maze can at least not be excluded.

Spontaneous, reinforced and delayed alternation in a 8 arm maze are not markedly affected by intrastriatal NMDA receptor blockade following stereotaxic injections of AP-5 as shown by experiment 2. Results indicate, that intrastriatal NMDA antagonism does not affect markedly spatial memory. Analysis of frequency of angles between arm entries which was recently reported to detect drug effects (McCann et al., 1987), also reveals no effects of AP-5 on the pattern of arm entries in an 8 arm maze (data not shown). In conclusion, striatal NMDA receptors within the prefrontal system seem not to be involved in spatial 
memory. This view is challenged by a study of Ryan et al. (1988), though using an other spatial task: in the Morris water task navigation deficits occur in rats with damage to the medial prefrontal cortex or anterior striatum, but this deterioration is not due to an impaired acquisition of spatial knowledge, but rather to a behavioral inflexibility interfering with spatial learning.

However, systemic NMDA receptor blockade with MK 801 result in a severe perturbation in 8 arm maze performance caused by a disturbed working memory (Bischoff et al., 1988). Therefore, 8 arm maze performance depend on intact glutamatergic transmission, but most probably in the hippocampus (Morris etal., 1986; Olton etal., 1979), while glutamatergic mechanisms within the striatum may be not implicated. Studies from Becker et al. (1978) support this view, since lesions in the medial frontal cortex as well as the caudate nucleus caused no change in radial maze performance.

Regarding underlying mechanisms resulting in impaired acquisition of delayed alternation in a T-maze, an increased susceptibility to interference may be a possible explanation. Delay task deficits after lesions of the prefrontal cortex as well as the related antero-dorsal striatum are often attributed to an exaggered sensitivity to interference (Fuster, 1981; Pisa, 1983; Simon and Le Moal, 1984). Insufficient control of variable internal and external stimuli competing with information storage over delays might account for increase of errors and in particular for much of the observed variability of errors on consecutive days by drugged animals in the T-maze. The sequential type of delayed alternation procedure used here may contribute to interference effects by different ways. Repetitive choices separated by delays i) increase the possibility of an impact of interfering stimuli and ii) constitute a potent source of proactive interference, because each choice may be influenced by all previous information received in preceding choices (Béracochéa and Jaffard, 1987). However, the involvement of proactive interference remains unclear, since an analysis of distribution from error frequencies over consecutive choices of the present data reveals, that error frequency is not significantly dependent on number of preceding choices. The observation that rats were impeded in acquisition of the T-maze task following intrastriatal injection of AP-5, support the view that the striatum participates in a system that suppresses the impact of stimuli interfering with storage of information over delays. In addition, the findings imply that inhibition of interference demand intact glutamatergic transmission. Following the proposed interpretation it seems reasonable that effects of intrastriatal NMDA receptor blockade in 8 arm maze tasks could not be detected for reasons of different requirements of T-maze and 8 arm maze tasks. First, it is known, that uninterrupted radial maze tasks as spontaneous or reinforced alternation are relatively resistant to pharmacological treatment (Burešova and Bureš, 1985) and a delay seems to be critical with regard to interference. Second, the delayed alternation task in a $8 \mathrm{arm}$ maze as used here probably permits no sufficient build-up of interference across successive choices resulting in a decrease in performance (Béracochéa and Jaffard, 1987), since only one mid-trial delay was 
interposed. Furthermore, it is possible that the four choices made before the mid-trital delay are perceived as a higher unit, remembering of which is facilitated (Bolhuis et al., 1985).

In conclusion, spatial orientation is not impaired in an 8 arm maze following intrastriatal NMDA receptor blockade. If striatal NMDA receptor blockade results in an increased vulnerability to interference as concluded from $\mathrm{T}$-maze experiments, this perturbation should be also present but may be not effective in 8 arm maze tasks, probably because the design of the tasks is inappropriate.

The results of our present study indicate that striatal NMDA receptors within the prefrontal system seem to be involved in the correct response retention over the duration of delays. The observed acquisition impairments of a delayed alternation task in a T-maze appears not to be due to a defective acquisition of spatial information per se; instead, repeated delays seem to be the critical component that give difficulties in acquisition. These difficulties in bridging successive temporal discontiguities after intrastriatal NMDA receptor blockade are attributed to an increased susceptibility to interference.

\section{Acknowledgements}

We are grateful to J. Wacker for her excellent technical assistance. This research was supported by the Deutsche Forschungsgemeinschaft.

\section{References}

Alessandri B, Welzl H, Bättig K (1988) Effects of the non-competitive NMDA antagonist ketamine on locomotor activity and memory formation in the rat. Eur $\mathrm{J}$ Neurosci [Suppl]: 323

Anis SC, Berry NR, Burton NR, Lodge D (1983) The dissociative anaesthetics, ketamine and phencyclidine, selectively reduce excitation of central mammalian neurones by $\mathrm{N}$ methyl-aspartate. Br J Pharmacol 79: 565-575

Becker TL, Walker JA, Olton DS, O'Conell BC (1978) Neuroanatomical bases of shortterm spatial memory in the rat. Society for Neuroscience Abstracts 4: 73

Béracochéa DJ, Jaffard R (1987) Impairment of spontaneous alternation behaviour in sequential test procedures following mamillary body lesions in mice: evidence for time dependent interference-related memory deficits. Behav Neurosci 101/2: 187-197

Bischoff C, Tiedtke PI, Schmidt WJ (1988) Learning in an 8-arm-radial-maze: effects of dopamine- and NMDA-receptor antagonists. In: Elsner N, Barth FG (eds) Sense organs. Proceedings of the 16th Göttingen Neurobiology Conference. G Thieme, Stuttgart, p 358

Bolhuis JJ, Burešová $\mathrm{O}$, Bureš $\mathbf{J}$ (1985) Persistence of working memory in an aversively motivated radial maze task. Behav Brain Res 15: 43-49

Burešová O, Bureš $J$ (1982) Radial maze as a tool for assessing the effect of drugs on the working memory of rats. Psychopharmacology 77: 268-271

Divac I, Öberg G (1979) The neostriatum. Pergamon Press, Oxford, pp 291-313

Douglas RJ, Isaacson RI (1965) Homogeneity of simple trial response tendencies and spontaneous alternation in the T-maze. Psychol Rep 16: 87-92

Dunnet SB, Iversen SD (1981) Learning impairments following selective kainic acid-induced lesions in the neostriatum of rats. Behav Brain Res 2: 189-209

Fonnum F (1984) Glutamate: a neurotransmitter in the mammalian brain. J Neurochem 42: $1-11$ 
Fuster JM (1981) The prefrontal cortex. Raven Press, New York, pp 41-84

Hauber W (1988) Striatal glutamate and maze performance. In: Elsner N, Barth FG (eds) Sense organs. Proceedings of th 16th Göttingen Neurobiology Conference. G Thieme, Stuttgart, p 357

Havemann U, Turski L, Schwarz M, Kuschinsky M (1983) Nigral GABAergic mechanisms and EMG activity in rats: differences between pars reticulata and pars compacta. Eur J Pharmacol 92: 49-56

Katz RJ, Schmaltz K (1981) Dopaminergic involvement in attention: a novel animal model. Prog Neuropsychopharmacol 4: 585-590

Koek W, Woods JH, Ornstein P (1987) A simple and rapid method for assessing similarities among directly observable behavioral effects of drugs: PCP-like effects of 2-amino-5phosphonovalerate in rats. Psychopharmacology 91: 297-304

Lienert GA (1973) Verteilungsfreie Methoden in der Biostatistik, Teil I. Anton Hain, Meisenheim, S 213-216

Markowitsch HJ, Pritzel M (1977) Comparative analysis of prefrontal learning functions in rats, cats and monkeys. Psychol Bull 84/5: 817-837

Martin D, Lodge D (1985) Ketamine acts as a non-competitive N-methyl-D-aspartate antagonist on frog spinal cord in vitro. Neuropharmacology 24: 999-1003

McCann DJ, Rabin RA, Winter JC (1987) Use of the radial maze in studies of phencyclidine and other drugs of abuse. Physiol Behav 40/6: 805-812

Monaghan DT, Cotman CW (1985) Distribution of N-methyl-D-aspartate-sensitive L(3H)glutamate-binding sites in rat brain. J Neurosci 11: 2909-2919

Montgomery KC (1954) The role of the exploratory drive in learning. J Comp Physiol Psychol 47: 60-64

Morris RGM, Anderson E, Lynch GS, Baudry M (1986) Selective impairment of learning and blockade of long-term-potentiation by a N-methyl-D-aspartate receptor antagonist, AP-5. Nature 319: 774-776

Nieuwenhuys P (1985) Chemocytoarchitecture of the brain. Springer, Berlin Heidelberg New York, pp 48-51

Olton DS, Becker JT, Handelmann GE (1979) Hippocampus, space and memory. Behav Brain Sci 2: 313-366

Olton DS, Samuelson RJ (1976) Remembrance of places passed: spatial memory in rats. J Exp Psychol [Anim Behav] 2: 97-116

Olvermann HJ, Jones AW, Watkins JC (1984) L-Glutamate has higher affinity than other amino acids for (3H)-D-AP-5 binding sites in rat brain membranes. Nature 307: 460-462

Paxinos G, Watson C (1982) The rat brain in stereotaxic coordinates. Academic Press, Sydney

Pisa $M$ (1983) Kainic acid injections into the rat neostriatum: effects on learning and exploration. In: Fuxe K, Roberts R, Schwarcz R (eds) Excitotoxins. Wenner-Gren Int Symp, vol 39. Macmillan, London

Rosvold HE (1968) The prefrontal cortex and caudate nucleus: a system for effecting correction in response mechanisms. In: Rupp E (ed) Mind as a tissue. Harper and Row, New York, pp 21-38

Ryan CN, Dunnett SB, Scheel-Krüger J (1988) Damage to the prefrontal cortex impairs spatial navigation learning but not the acquisition of spatial knowledge. Psychopharmacology 96/1: p 48

Sandberg M, Ward HK, Bradford HF (1985) Effects of cortico-striate pathway lesion on the activities of enzymes involved in synthesis and metabolism of amino acid neurotransmitters in the striatum. J Neurochem 44: 42-44

Simon H, Le Moal M (1984) Mesencephalic dopaminergic neurons; functional role. In: Catecholamines: neuropharmacology and central nervous system. Theoretical aspects. Alan R Liss, New York, pp 293-307 
Scheel-Krüger J, Vrijmoed-De Vries MC (1986) Distinct functional effects of glutamic acid and dopamine within various regions of the striatum. Neurosci Lett [Suppl] 26: p 27

Schmidt WJ (1986) Intrastriatal injection of d1-2-amino-5-phosphonovaleric acid (AP-5) induces sniffing that is antagonized by haloperidol and clozapine. Psychopharmacology 90: $123-130$

Schmidt WJ, Bury D (1988) Behavioural functions of N-methyl-D-aspartate (NMDA) in the antero-dorsal striatum of the rat. Life Sci 43/6: 545-549

Schmidt WJ, Bubser M (1987) 6-Hydroxydopamine lesions of the prefrontal cortex reduce stereotypy and enhance catalepsy. In: Elsner N, Creutzfeldt $O$ (eds) New frontiers in brain research. Proc, 15 th Göttingen Neurobiology Conference. G Thieme, Stuttgart, p 278

Turski L (1988) Muscle relaxant action of excitatory amino acid antagonists: sites of action. Neurochem Int 12 [Suppl 1]: 11

Turski WA, Sonntag KH (1988) Basal ganglia and motor control in the rat: effect of intrastriatal and intrapallidal 2-amino-7-phosphonoheptanoate on motility. Neurochem Int 12 [Suppl 1]: p 35

Walaas I (1981) Biochemical evidence for overlapping neocortical and allocortical projections to the nucleus accumbens and rostral caudatoputamen in the rat brain. Neuroscience 6: 399-405

Wikmark RGE, Divac I, Weiss R (1973) Retention of spatial delayed alternation in rats with lesions in the frontal lobes. Brain Behav Evol 8: 329-339

Authors' address: W. Hauber, Abteilung Verhaltenspharmakologie, Universität Tübingen, Mohlstrasse 54/1, D-7000 Tübingen, Federal Republic of Germany.

Received October 13, 1988 